\title{
The Effects of Adverse Childhood Experiences on Self-Reported Physical and Mental Health Outcomes in Adulthood
}

\author{
Chong-Hwan Son \\ Hudson Valley Community College, New York, U.S.A. \\ c.son@hvcc.edu
}

\begin{abstract}
The number of physically and mentally unhealthy days as a measure of health-related quality of life (HRQOL) is used to examine the different effects of the adverse childhood experiences (ACEs) on physical and mental health outcomes. The data, a cross-sectional state-level survey, is obtained from the Behavioral Risk Factor Surveillance System (BRFSS) collected by the Centers for Disease Control and Prevention (CDC) in 2012. Multiple regression analyses are conducted for the study. The results indicate that all individual ACE categories are inversely associated with both physical and mental health, as respondents who exposed to any adverse childhood experience are likely to have physically- and mentally-related poor HRQOL in adulthood. The estimated coefficients for individual ACEs in magnitude on the mental health outcome are, in overall, greater than the estimated coefficients on the physical health outcome. The regression results with accumulative ACE scores indicate that higher levels of the ACE score would affect higher negative health outcomes, such as the dosage effects that appear again in this study. The estimated coefficients of accumulative ACE scores on the mental health outcome exceed the coefficients of ACE scores on physical health outcome for an ACE score of 2 and above. The gap in the estimated coefficients of ACE scores between physically and mentally unhealthy days increases as the ACE score rises. The estimated coefficient at the score ACE8 for the mentally unhealthy days becomes almost twice as large as the coefficient for the physically unhealthy days. Importantly, the negative effects of ACEs on mental health outcomes are significantly greater than the negative effects on physical health outcomes.
\end{abstract}

Keywords: Health-Related Quality of Life, Adverse Childhood Experiences, Number of Unhealthy Days, BRFSS, Alcohol Impaired Driving Behavior

\section{Introduction}

A traditional public health measure of the morbidity and mortality, the quality of life, would be physical examination and other objective procedures or test at the individual level, at clinics and hospitals. It could be limited to individuals' subjective assessment of their lives. The measure of mortality and morbidity rates provides only a partial picture of public health needs and prevention outcomes. The concept of health-related quality of life (HRQOL) encompass the aspects of overall quality of life, and its determinants have developed gradually since the 1980s (Cerne et al., 2013; Theofilou, 2013). HRQOL consists extensively of the physical, emotional, mental, social, and behavioral components of well-being and function as perceived by individuals (Theofilou, 2013), such as aspects of life satisfaction and happiness. The measurement of HRQOL has established a practical guide to the interventions and monitor progress of achieving the nation's health objectives. HRQOL questions about perceived physical and mental health and function have become an important component of health surveillance and are generally considered valid indicators of service needs and intervention outcomes. HRQOL is used increasingly as outcome measures in evaluation of care for chronic disorders, and measures of HRQOL are strong predictors of mortality, disease complications, and resource use (Heslin et al., 2011).

Adverse childhood experiences (ACE), including abuse and family dysfunction, impact more than $50 \%$ of the U.S. population and are increasingly recognized to have powerful adverse effects on health at all life stages and on victims' socio-economic well-being in adulthood (Liu et al., 2013; Schüsseler-Fiorenza Rose et al., 2014). According to the study Anda et al. (2006) that reviewed the previous literature, early life stress such as abuse and related adverse experiences influence enduring brain dysfunction that, successively, affects health and quality of life throughout the lifespan. Also, increasing ACE level has been linked to a range of adverse 
physical and mental health outcomes in adulthood (Chapman et al., 2013; Liu et al., 2013; Mersky et al., 2013). More specifically, as the number of adverse experiences increases, the likelihood of mental and physical health complications also increases. The concept is often referred as a dosage. In short, the literature has arrived at consistent conclusions that ACEs are adversely associated with a variety of health outcomes in adulthood. Although such evidence for negative consequences of the ACEs on health outcomes has come, research has yet to employ the different effects of ACEs on physical health outcomes and mental health outcomes. Thus, this study investigates the different effects of ACEs on HRQOL between physical and mental health outcomes in adulthood. This study could contribute to the literature by providing additional insight to HRQOL related to the ACEs for enhancing physical and mental health outcomes in adulthood and further understanding of the effects of ACEs on physical and mental health outcomes.

The data for this study, a cross-sectional state-level survey, is obtained from the Behavioral Risk Factor Surveillance System (BRFSS) collected by the Centers for Disease Control and Prevention (CDC) in 2012. The BRFSS is a surveillance system operated by the state health departments in collaboration with CDC. HRQOL, one of the core modules in the BRFSS questionnaires, has three questions to monitor both self-reported physically and mentally unhealthy days. The numbers of unhealthy days as a measure of the HRQOL are dependent variables in the analytical models. All explanatory variables are also taken from the 2012 BRFSS, including socio-demographic variables, health behavioral variables, and childhood adverse experiences. This study uses a structural equation modeling framework because it allows the author to focus on two equally important outcomes: physical and mental health as it does in traditional regression analysis for outcomes of HRQOL (Huang et al., 2012; Simms et al., 2013). The value of the intercept becomes meaningful because it is the average value of the dependent variable when all the predictors are zero.

\section{Analytical Framework}

Medical care, social policies, and environmental factors as health-related features of neighborhoods have been the core determinants of health outcomes in public health research. The facts supported by previous researches have accumulated. Literature has, however, pointed to socioeconomic factors, such as income, wealth, and education as the fundamental causes of a wide range of health outcomes (Braveman \& Gottlieb, 2014; Meyer et al., 2014). The following model of health outcomes is developed since the HRQOL as a measure of health outcomes is the dependent variable.

$h=h(d, z)$

Where ' $h$ ' represents a health outcome measure of HRQOL from the BRFSS. The HRQOL is gauged in numbers of both physically and mentally unhealthy days during the past 30 days. The number of unhealthy days ranges from 0 to 30 days, with a logical maximum of 30 unhealthy days per month, treated as continuous variables (Clifford et al., 2013; Mahabaleshwarkar et al., 2013). 'd' represents a group of socio-demographic and selected health behavior variables. ' $\mathrm{z}$ ' subsumes all other relevant factors of health outcomes, mainly adverse childhood experiences. Studies (Mersky et al., 2013; Montgomery et al., 2013; Simms et al., 2013) have consistently shown that adverse childhood experiences have been linked to increase in the risk of poor health related outcomes in adulthood. Both individual categories of and cumulative scores of eight adverse childhood experiences on physical and mental health outcomes in adulthood are separately examined in the empirical models.

$\mathrm{h}_{\mathrm{i}}=\beta_{0}+\mathrm{x}_{\mathrm{ik}} \beta_{\mathrm{k}}+\mathrm{u}_{\mathrm{i}}$

where subscript $\mathrm{i}$ denotes observation, and $\mathrm{h}_{\mathrm{i}}$ is the continuous dependent variable of the $\mathrm{i}^{\text {th }}$ observation. $\beta_{0}$ is a fixed non-random constant, and $x_{i k}$ are independent random variables with zero mean value and constant standard error $\sigma_{\mathrm{x}}$. $\mathrm{x}_{\mathrm{ik}}$ is an i $\mathrm{x}$ k matrix of explanatory variables where $\mathrm{k}$ represents the number of explanatory variables including state dummy variables. This state fixed effect model removes the effects of differences associated with other relevant independent variables among states on the dependent variables and captures the effects of unobserved state specific variables. For example, residents in higher and lower income states may have different profiles of risk factors for health outcomes because people who live in lower income states are likely to exhibit a lower level of demand for medical and healthcare services than people who live in 
higher income states. $\beta_{\mathrm{k}}$ is a coefficients matrix of the equation with a dimension $\mathrm{kx} 1 . \mathrm{u}_{\mathrm{i}}$ is an error term of each observation i with zero mean and constant standard error $\sigma_{\mathrm{u}}$. It is generally assumed that $\operatorname{Cov}\left(\mathrm{x}_{\mathrm{ik}}, \mathrm{u}_{\mathrm{i}}\right)=0$ (Mesbah, 2004; Jia \& Lubetkin, 2009; Son \& Lee, 2014). With expected value of $u_{i}, E\left(u_{i}\right)=0$, the conditional expected value of dependent variable is $E\left(h_{i} \mid x_{i k}\right)=\beta_{0}+x_{i k} \beta_{k}$. From the regression equation (DuMouchel \& Duncan, 1983),

$\hat{\mathrm{h}}_{\mathrm{i}}=\hat{\beta}_{0}+\mathrm{x}_{\mathrm{ik}} \hat{\beta}_{\mathrm{i}}$

Where $\hat{h}_{i}, \hat{\beta}_{0}$, and $\hat{\beta}_{\mathrm{i}}$ are estimated numbers of unhealthy days, estimated constant, and estimated coefficients of the explanatory variables respectively. The weights were not employed in the regression estimates since studies (DuMouchel \& Duncan, 1983; Maddala, 1992; Chou et al., 2004; Son \& Lee, 2014) have shown that this is not required in the case of exogenous stratification.

\section{Empirical Implementation}

Data from the 2012 BRFSS is used to investigate the different effects of ACEs on physical and mental health outcomes as measures of HRQOL in adulthood. The BRFSS is a surveillance system operated by state health departments that follow guidelines provided by CDC. Since the BRFSS was originally designed to collect the state-level data, some states from the beginning stratified population to allow them to collect region-wise data in their own states. The survey has been tracking the health conditions and health related risk behaviors of adults aged 18 and older in the United States since 1984. In 2012, data are collected from 50 states, the District of Columbia, Guam, Puerto Rico, and the U.S. Virgin Islands. The BRFSS conducts both landline telephone- and cellular telephone-based survey. The detailed information of the 2012 BRFSS survey design, data collection, and the codebook of the survey questionnaires can be available at http://www.cdc.gov/brfss/annual_data/annual_2012.html.

Table 1: Definition, Mean, and Standard Deviations of Variables ${ }^{a}$

\begin{tabular}{|c|c|c|}
\hline Variable & Definition & Mean and S.D. \\
\hline PHYSHLTH & Number of days when physical health was not good during the past 30 days. & $3.784(8.271)$ \\
\hline MENTHLTH & Number of days when mental health was not good during the past 30 days. & $3.667(8.006)$ \\
\hline Age & Age of respondent. & $\begin{array}{l}47.571 \\
(17.158)\end{array}$ \\
\hline Male & Dichotomous variable that equals 1 if respondent is male. & $0.508(0.500)$ \\
\hline Married & Dichotomous variable that equals 1 if respondent is married. & $0.591(0.492)$ \\
\hline Less high school & $\begin{array}{l}\text { Dichotomous variable that equals } 1 \text { if respondent completed less than } 12 \text { years of } \\
\text { formal schooling. }\end{array}$ & $0.117(0.321)$ \\
\hline Employed & Dichotomous variable that equals 1 if respondent is employed for wages. & $0.519(0.500)$ \\
\hline Less $\$ 20,000$ & $\begin{array}{l}\text { Dichotomous variable that equals } 1 \text { if annual household income less than } \\
\$ 20,000 \text {. }\end{array}$ & $0.194(0.395)$ \\
\hline $\begin{array}{l}\text { White non- } \\
\text { Hispanic }\end{array}$ & Dichotomous variable that equals 1 if respondent is White, but not Hispanic. & $0.791(0.407)$ \\
\hline Body mass index & Weight in kilograms divided by square of height in meters. & $28.160(6.194)$ \\
\hline Current smokers & $\begin{array}{l}\text { Dichotomous variable that equals } 1 \text { if respondent now smokes cigarettes every } \\
\text { day or some days. }\end{array}$ & $0.213(0.410)$ \\
\hline Current drinkers & $\begin{array}{l}\text { Dichotomous variable that equals } 1 \text { if respondent had at least one drink of alcohol } \\
\text { in the past } 30 \text { days }^{\text {b. }}\end{array}$ & $0.530(0.499)$ \\
\hline Current exercise & $\begin{array}{l}\text { Dichotomous variable that equals } 1 \text { if respondent participates in any physical } \\
\text { activities or exercises such as running, calisthenics, golf, gardening, or walking for } \\
\text { exercise during the past month. }\end{array}$ & $0.771(0.420)$ \\
\hline
\end{tabular}

a. Standard deviations are in parentheses. Means and standard deviations are weighted by the BRFSS sample weight factor. All means are statistically significant using two tailed t-test with $95 \%$ confidence interval. $b$. One drink is equivalent to a 12 -ounce beer, a 5-ounce glass of wine, or a drink with one shot of liquor.

The BRFSS questionnaire primarily consists of a core component as a standard set of questions asked by all states, optional CDC modules supported by CDC as sets of questions on specific topics that states select to use on their questionnaires, and state-added questions as questions developed or acquired by participating states 
which are added to their questionnaires. Each year, the states and CDC agree on the content of the core component and optional modules. ACEs belong to the optional modules. In 2012, only five states (Iowa, North Carolina, Oklahoma, Tennessee, and Wisconsin) implemented the ACEs module. The total baseline observations for the five states in 2012 BRFSS data were 39,434. Excluding observations for each variable due to missing values, unanswered questions, don't know/not sure, questions not asked, and refusals, 22,987 (58.29\%) of adults aged 18 years or older completed all questions pertaining to perceived numbers of physically/mentally unhealthy days, socio-demographic and health behavior variables, and ACEs. Descriptions and summary statistics of the dependent and independent variables are presented in Table 1 and Table 2. The means and standard deviations in the tables are computed based on BRFSS sampling weights (see details at http://www.cdc.gov/brfss/annual_data/2012/pdf/overview_2012.pdf).

Dependent variables: HRQOL, also called the Health Days module, includes three questions that measure the self-reported health. The first two questions report the number of days during the past 30 days in which the respondent's physical or mental health was not good. Physical health was measured by the question, "Now thinking about your physical health, which includes physical illness and injury, for how many days during the past 30 days was your physical health not good?" Mental health was measured by the question, "Now thinking about your mental health, which includes stress, depression, and problems with emotions, for how many days during the past 30 days was your mental health not good?" These two measures are served as outcome variables of HRQOL in this study. The number of unhealthy days ranges from 0 to 30 days, with a logical maximum of 30 unhealthy days per month. The measures of HRQOL scale have been tested and established for their validity and reliability in previous studies (Anderson et al., 2003; Brown et al., 2004; Evenson \& McGinn, 2005) and have been widely used in public health studies. The third question is the number of activity limitation days because of poor physical or mental health during the past 30 days.

Clinicians and clinical researchers often used the 14-day minimum period of poor health condition for their studies. Studies (Ford et al., 2008; Heath \& Brown, 2009; Chen et al., 2011) construct the numbers of unhealthy days into mutually exclusive categories using 14 days or more as the cutoff value for determining the chronic presence of physical or mental problems. For the same measure of unhealthy days for the HRQOL, the study by Clifford et al. (2013) dichotomizes the unhealthy days using reporting of no unhealthy days per month (none) versus reporting of one or more unhealthy days (1-30) per month. Some other studies use the measures of unhealthy days as continuous measures (Jia \& Lubetkin, 2009; Zullig \& Hendryx, 2010). The author concerns the problematic method about the threshold of 14 days or more for the unhealthy days. Hypothetically, a respondent with zero unhealthy days during the past 30 days is indifferent in the empirical analysis from a respondent with 13 unhealthy days if a study sets the cutoff value. Using the numbers of unhealthy days as dependent variables in this study, participants reported the more unhealthy days during the past month as the poorer the HRQOL. The average numbers of unhealthy days due to physical and mental health problem are 3.784 days and 3.667 days respectively during the 30 days (Table 1). 64.73\%, 69.55\%, and $51.02 \%$ of participants did not have any unhealthy days because of physical, mental, and both physical and mental health problems respectively.

Explanatory Variables: Socio-demographic variables consist of age, gender, marital status, education, employment status, income, and race/ethnicity; behavioral variables include BMI, smoking, alcohol drinking, and exercise. These variables are widely used in HRQOL studies (Mahabaleshwarkar et al., 2013; Braveman \& Gottlieb, 2014; Meyer et al., 2014). The means and standard deviations are shown in Table 1.

The socio-demographic variables: Studies (Miles \& Proescholdbell, 2011; Clifford et al., 2013) analyze the determinants of HRQOL. The studies find that aging is significantly associated with physically/mentally unhealthy days. In the BRFSS survey questionnaire, all participants are asked for their ages. Average age of all respondents in the five states is 47.57 years. Studies (Heath \& Brown, 2009; Clifford et al., 2013) examine the relationship between gender and measures of HRQOL. They find that gender is a significant predictor for HRQOL and that females have a higher risk of both physically and mentally unhealthy days. $50.8 \%$ of survey participants in the five states are males. The respondents' marital status is divided into six categories; married, divorced, widowed, separated, never married, and a member of an unmarried couple. Marital status in this study represents married respondents which are $59.1 \%$ of all respondents. The study by Wang (2008) finds that respondents who get a higher education have a high perception of their health status. Level of 
education is negatively associated with the number of days physical/mental health was not good during the past 30 days. Participants completed less than 12 years of formal schooling (less than high school) as education status is dichotomized. $11.7 \%$ of respondents in the current data completed less than high school. In the BRFSS, eight mutually exclusive categories of employment status are asked, such as employed for wages, self-employed, out of work for more than 1 year, out of work for less than 1 year, a homemaker, a student, retired, and unable to work as employed others. This paper retains only the employed for wages as employment status. $51.9 \%$ of respondents are employed for wages. Lower income people might be likely to exhibit a lower level of demand for medical and health services than higher income people because their spending on healthcare would be lower. The BRFSS asks participants for their annual household income. This study uses only one income category as a respondent's annual household income is less than $\$ 20,000.19 .4 \%$ of participants in the five states earned their annual household income less than $\$ 20,000$ in 2012 . Survey participants are also asked for race/ethnicity. $79.1 \%$ of the BRFSS survey participants in the five states were White, non-Hispanic. Studies (Montgomery et al., 2013; Simms et al., 2013) examine health outcomes among several categorical races in adulthood. The results indicate that White, non-Hispanic, in general, are less likely to have physically and mentally unhealthy days than other races.

The health behavioral variables: Body Mass Index (BMI) represents a relative weight for height. BMI is calculated by weight $(\mathrm{kg})$ divided by height (meter) squared. Since height and weight in BRFSS are reported in feet/inches and pounds, height is converted to meters by multiplying 2.54 to the height in inches, and then dividing it by 100 . Weight is also converted to kilograms by dividing weight in pounds by 2.2 . BMI is significantly correlated to total volume of body fat. The average BMI is $28.16 \mathrm{~kg} / \mathrm{m}$ for all participants in the five states. A current smoker is defined as a respondent who now smokes every day or some days. $21.3 \%$ of respondents are current smokers. A respondent is considered as a current drinker if the respondent who reported had at least one drink of alcohol in the past 30 days. One drink is equivalent to a 12 -ounce beer, a 5ounce glass of wine, or a drink with one shot of liquor. $53.0 \%$ of respondents are considered as current drinkers. Physical activity is defined as physical activities or exercise other than a person's job-related regular activities during the past month, including running, calisthenics, golf, gardening, or walking for exercise. 77.1\% of survey respondents reported any participation in physical activities.

Adverse Childhood Experiences: In the 2012 BRFSS survey, the five states administered the optional ACE module in which a total of 11 questions about ACEs was asked to the participants. Three of those questions asked about sexual abuse: "How often did anyone at least 5 years older than you or an adult, ever touch you sexually?; ..., try to make you touch them sexually?; and ..., force you to have sex?" A response of either 'once' or 'more than once' to any of above three questions is defined as sexual abuse. The substance abuse category is combined with the following two abuse ACE modules: "Did you live with anyone who was a problem drinker or alcoholic?" and "Did you live with anyone who used illegal street drugs or who abused prescription medications?" Eventually the 11 ACE questions were grouped into 8 ACE categories that included three categories of child abuse (physical, emotional, and sexual abuse) and five categories of household dysfunction (mental illness, substance abuse, incarnation, separation or divorce, and domestic violence). All ACE variables are dichotomized as one if respondents answered "yes" to each question. The definitions, means, and standard deviations of the ACEs are shown in Table 2.

Previous ACE studies (Brown et al., 2013; Chapman et al., 2013; Mersky et al., 2013) report that ACEs are highly interrelated. Respondents who experience one ACE increase significantly the likelihood of reporting exposure to multiple ACEs. Other studies (Chartier et al., 2010; Adam et al., 2011) have importantly concluded that the character of individual adverse experiences was not the most powerful predictor for physical and mental health outcomes in adulthood. According to their findings, it was a matter of the number of adverse experiences, known as a dosage effect. Also, the study by Simms et al. (2013) reports that the number of adverse experiences provides the most explanatory power in predicting physical and mental health rather than the specific character of individual ACE category. Regarding the dosage effect, this study substitutes the ACE scores for the individual ACE categories in the empirical models to evaluate the dosage effect of ACEs on HRQOL. The ACE scores are computed by summing the total number of ACE categories for each observation (Mostoufi et al., 2013; Mersky et al., 2013). Nine categories of ACE scores (0, 1, 2, 3, 4, 5, 6, 7, and 8) are implemented in the analyses, with zero experiences serving as the reference (Liu et al., 2013; Schüsseler-Fiorenza Rose et al., 2014). 
Table 2: Definition, Mean, and Standard Deviations of Eight Categories of Adverse Childhood Experiences ${ }^{\mathbf{a}}$

\begin{tabular}{|c|c|c|}
\hline Variable & Definition & $\begin{array}{l}\text { Mean and } \\
\text { S.D. }\end{array}$ \\
\hline Physical abuse & $\begin{array}{l}\text { Dichotomous variable that equals } 1 \text { if a parent or adult ever hit, beat, } \\
\text { kick, or physically hurt the respondents once or more than once in any } \\
\text { way, not including spanking. }\end{array}$ & $0.149(0.356)$ \\
\hline $\begin{array}{l}\text { Emotional } \\
\text { abuse }\end{array}$ & $\begin{array}{l}\text { Dichotomous variable that equals } 1 \text { if a parent or adult ever swear at the } \\
\text { respondent, insult the respondent, or put the respondent down once or } \\
\text { more than once. }\end{array}$ & $0.326(0.469)$ \\
\hline Sexual abuse & $\begin{array}{l}\text { Dichotomous variable that equals } 1 \text { if anyone at least } 5 \text { years older than } \\
\text { the respondents or an adult ever touch sexually/try to make the } \\
\text { respondent touch them sexually/force the respondent to have sex once } \\
\text { or more than once. }\end{array}$ & $0.108(0.311)$ \\
\hline Mental Illness & $\begin{array}{l}\text { Dichotomous variable that equals } 1 \text { if respondent live with anyone who } \\
\text { was depressed, mentally ill, or suicidal. }\end{array}$ & $0.164(0.370)$ \\
\hline Substance abuse & $\begin{array}{l}\text { Dichotomous variable that equals } 1 \text { if respondent live with anyone who } \\
\text { was a problem drinker or alcoholic/who used illegal street drugs or who } \\
\text { abused prescription medications. }\end{array}$ & $0.272(0.445)$ \\
\hline Incarceration & $\begin{array}{l}\text { Dichotomous variable that equals } 1 \text { if respondent live with anyone who } \\
\text { served time or was sentenced to serve time in a prison, jail, or other } \\
\text { correctional facility. }\end{array}$ & $0.080(0.272)$ \\
\hline $\begin{array}{l}\text { Separation } \\
\text { divorce }\end{array}$ & $\begin{array}{l}\text { Dichotomous variable that equals } 1 \text { if respondent's parents were } \\
\text { separated or divorced. }\end{array}$ & $0.273(0.445)$ \\
\hline $\begin{array}{l}\text { Domestic } \\
\text { violence }\end{array}$ & $\begin{array}{l}\text { Dichotomous variable that equals } 1 \text { if parents or adults ever slap, hit, } \\
\text { kick, punch or beat each other up once or more than once. }\end{array}$ & $0.170(0.375)$ \\
\hline ACE0 & $\begin{array}{l}\text { Dichotomous variable that equals } 1 \text { if the total number of ACEs } \\
\text { respondents reported equals } 0 \text {. }\end{array}$ & $0.390(0.488)$ \\
\hline ACE1 & $\begin{array}{l}\text { Dichotomous variable that equals } 1 \text { if the total number of ACEs } \\
\text { respondents reported equals one. }\end{array}$ & $0.242(0.428)$ \\
\hline ACE2 & $\begin{array}{l}\text { Dichotomous variable that equals } 1 \text { if the total number of ACEs } \\
\text { respondents reported equals two. }\end{array}$ & $0.127(0.333)$ \\
\hline ACE3 & $\begin{array}{l}\text { Dichotomous variable that equals } 1 \text { if the total number of ACEs } \\
\text { respondents reported equals three. }\end{array}$ & $0.087(0.282)$ \\
\hline ACE4 & $\begin{array}{l}\text { Dichotomous variable that equals } 1 \text { if the total number of ACEs } \\
\text { respondents reported equals four. }\end{array}$ & $0.062(0.240)$ \\
\hline ACE5 & $\begin{array}{l}\text { Dichotomous variable that equals } 1 \text { if the total number of ACEs } \\
\text { respondents reported equals five. }\end{array}$ & $0.044(0.206)$ \\
\hline ACE6 & $\begin{array}{l}\text { Dichotomous variable that equals } 1 \text { if the total number of ACEs } \\
\text { respondents reported equals six. }\end{array}$ & $0.026(0.158)$ \\
\hline ACE7 & $\begin{array}{l}\text { Dichotomous variable that equals } 1 \text { if the total number of ACEs } \\
\text { respondents reported equals seven. }\end{array}$ & $0.017(0.128)$ \\
\hline ACE8 & $\begin{array}{l}\text { Dichotomous variable that equals } 1 \text { if the total number of ACEs } \\
\text { respondents reported equals eight. }\end{array}$ & $0.006(0.077)$ \\
\hline
\end{tabular}

From the 2012 BRFSS in the five states, $61 \%$ of respondents reported having at least one ACE, and 9.2\% reported as having five or more ACEs during childhood. For individual ACE categories, the prevalence of each of ACE ranged from a high of $32.6 \%$ for emotional abuse to a low of $8.0 \%$ for the incarceration category (Table 2). Participants who answered "don't know/not sure" for each of ACE questions were excluded, although earlier literatures have shown different consideration for the setting. The study (Liu et al., 2013) includes that respondents who answer "don't know" or "not sure" to any one of the ACE questions are considered not to have had an ACE for that category. On the other hand, the study (Chapman et al., 2013; Schüsseler-Fiorenza Rose et al., 2014) uses the same approach of coding answers of "do not know" as a 
negative response for the ACE category. Additionally the study by Ford et al. (2011) calculates the prevalence of current smoking according to exposure to each of the eight ACEs which answered only "yes/no."

\section{Analysis and Results}

Table 3: Prevalence of Individual Adverse Childhood Experiences by Selected Variables ${ }^{\mathrm{a}}$

\begin{tabular}{lllllllllll}
\hline ACE & $\begin{array}{l}\text { All } \\
\text { adults }\end{array}$ & Male & Married & $\begin{array}{l}\text { Less } \\
\text { high } \\
\text { school }\end{array}$ & Employed & $\begin{array}{l}\text { Less } \\
\mathbf{\$ 2 0 , 0 0 0}\end{array}$ & $\begin{array}{l}\text { White } \\
\text { non- } \\
\text { Hispanic }\end{array}$ & $\begin{array}{l}\text { Current } \\
\text { smokers }\end{array}$ & $\begin{array}{l}\text { Current } \\
\text { drinkers }\end{array}$ & $\begin{array}{l}\text { Current } \\
\text { exercise }\end{array}$ \\
\hline Physical & 0.149 & 0.147 & 0.138 & 0.225 & 0.144 & 0.220 & 0.145 & 0.217 & 0.150 & 0.144 \\
abuse & $(0.356)$ & $(0.354)$ & $(0.345)$ & $(0.418)$ & $(0.351)$ & $(0.414)$ & $(0.352)$ & $(0.412)$ & $(0.357)$ & $(0.351)$ \\
Emotional & 0.326 & 0.322 & 0.307 & 0.330 & 0.338 & 0.388 & 0.330 & 0.422 & 0.356 & 0.332 \\
abuse & $(0.469)$ & $(0.467)$ & $(0.461)$ & $(0.470)$ & $(0.473)$ & $(0.487)$ & $(0.470)$ & $(0.494)$ & $(0.479)$ & $(0.471)$ \\
Sexual abuse & 0.108 & 0.063 & 0.098 & 0.133 & 0.098 & 0.155 & 0.104 & 0.168 & 0.107 & 0.102 \\
& $(0.311)$ & $(0.242)$ & $(0.298)$ & $(0.340)$ & $(0.297)$ & $(0.362)$ & $(0.305)$ & $(0.373)$ & $(0.309)$ & $(0.303)$ \\
Mental & 0.164 & 0.132 & 0.149 & 0.160 & 0.160 & 0.212 & 0.174 & 0.236 & 0.172 & 0.166 \\
Illness & $(0.370)$ & $(0.338)$ & $(0.356)$ & $(0.367)$ & $(0.367)$ & $(0.409)$ & $(0.379)$ & $(0.425)$ & $(0.377)$ & $(0.372)$ \\
Substance & 0.272 & 0.254 & 0.253 & 0.368 & 0.268 & 0.361 & 0.265 & 0.398 & 0.273 & 0.270 \\
abuse & $(0.445)$ & $(0.435)$ & $(0.435)$ & $(0.482)$ & $(0.443)$ & $(0.480)$ & $(0.442)$ & $(0.490)$ & $(0.445)$ & $(0.444)$ \\
Incarceration & 0.080 & 0.082 & 0.056 & 0.167 & 0.078 & 0.145 & 0.067 & 0.160 & 0.085 & 0.080 \\
& $(0.272)$ & $(0.274)$ & $(0.229)$ & $(0.373)$ & $(0.268)$ & $(0.352)$ & $(0.251)$ & $(0.367)$ & $(0.280)$ & $(0.271)$ \\
Separation & 0.273 & 0.269 & 0.234 & 0.350 & 0.289 & 0.358 & 0.249 & 0.399 & 0.281 & 0.272 \\
or divorce & $(0.445)$ & $(0.443)$ & $(0.423)$ & $(0.477)$ & $(0.453)$ & $(0.479)$ & $(0.433)$ & $(0.490)$ & $(0.449)$ & $(0.445)$ \\
Domestic & 0.170 & 0.155 & 0.155 & 0.259 & 0.169 & 0.249 & 0.156 & 0.247 & 0.165 & 0.161 \\
violence & $(0.375)$ & $(0.362)$ & $(0.362)$ & $(0.438)$ & $(0.375)$ & $(0.433)$ & $(0.363)$ & $(0.431)$ & $(0.372)$ & $(0.368)$ \\
\hline
\end{tabular}

a. Standard deviations are in parentheses. Means and standard deviations are weighted by the BRFSS sample weight factor. All means are statistically significant using two tailed t-test with $95 \%$ confidence interval.

Table 4: Prevalence of Accumulative Adverse Childhood Experiences by Selected Variables ${ }^{a}$

\begin{tabular}{|c|c|c|c|c|c|c|c|c|c|c|}
\hline ACE Score & $\begin{array}{l}\text { All } \\
\text { adults }\end{array}$ & Male & Married & $\begin{array}{l}\text { Less } \\
\text { high } \\
\text { school }\end{array}$ & Employed & $\begin{array}{l}\text { Less } \\
\$ 20,000\end{array}$ & $\begin{array}{l}\text { White } \\
\text { non- } \\
\text { Hispanic }\end{array}$ & $\begin{array}{l}\text { Current } \\
\text { smokers }\end{array}$ & $\begin{array}{l}\text { Current } \\
\text { drinkers }\end{array}$ & $\begin{array}{l}\text { Current } \\
\text { exercise }\end{array}$ \\
\hline ACE0 & $\begin{array}{l}0.390 \\
(0.488)\end{array}$ & $\begin{array}{l}0.397 \\
(0.489)\end{array}$ & $\begin{array}{l}0.418 \\
(0.493)\end{array}$ & $\begin{array}{l}0.318 \\
(0.466)\end{array}$ & $\begin{array}{l}0.375 \\
(0.484)\end{array}$ & $\begin{array}{l}0.316 \\
(0.465)\end{array}$ & $\begin{array}{l}0.405 \\
(0.491)\end{array}$ & $\begin{array}{l}0.267 \\
(0.442)\end{array}$ & $\begin{array}{l}0.366 \\
(0.482)\end{array}$ & $\begin{array}{l}0.393 \\
(0.488)\end{array}$ \\
\hline ACE1 & $\begin{array}{l}0.242 \\
(0.428)\end{array}$ & $\begin{array}{l}0.258 \\
(0.438)\end{array}$ & $\begin{array}{l}0.244 \\
(0.429)\end{array}$ & $\begin{array}{l}0.221 \\
(0.415)\end{array}$ & $\begin{array}{l}0.254 \\
(0.435)\end{array}$ & $\begin{array}{l}0.202 \\
(0.401)\end{array}$ & $\begin{array}{l}0.245 \\
(0.430)\end{array}$ & $\begin{array}{l}0.213 \\
(0.410)\end{array}$ & $\begin{array}{l}0.256 \\
(0.437)\end{array}$ & $\begin{array}{l}0.243 \\
(0.429)\end{array}$ \\
\hline ACE2 & $\begin{array}{l}0.127 \\
(0.333)\end{array}$ & $\begin{array}{l}0.132 \\
(0.339)\end{array}$ & $\begin{array}{l}0.127 \\
(0.332)\end{array}$ & $\begin{array}{l}0.123 \\
(0.329)\end{array}$ & $\begin{array}{l}0.131 \\
(0.338)\end{array}$ & $\begin{array}{l}0.119 \\
(0.324)\end{array}$ & $\begin{array}{l}0.122 \\
(0.327)\end{array}$ & $\begin{array}{l}0.137 \\
(0.344)\end{array}$ & $\begin{array}{l}0.127 \\
(0.333)\end{array}$ & $\begin{array}{l}0.128 \\
(0.334)\end{array}$ \\
\hline ACE3 & $\begin{array}{l}0.087 \\
(0.282)\end{array}$ & $\begin{array}{l}0.081 \\
(0.273)\end{array}$ & $\begin{array}{l}0.082 \\
(0.274)\end{array}$ & $\begin{array}{l}0.109 \\
(0.312)\end{array}$ & $\begin{array}{l}0.091 \\
(0.288)\end{array}$ & $\begin{array}{l}0.115 \\
(0.319)\end{array}$ & $\begin{array}{l}0.081 \\
(0.274)\end{array}$ & $\begin{array}{l}0.117 \\
(0.321)\end{array}$ & $\begin{array}{l}0.094 \\
(0.292)\end{array}$ & $\begin{array}{l}0.086 \\
(0.280)\end{array}$ \\
\hline ACE 4 & $\begin{array}{l}0.062 \\
(0.240)\end{array}$ & $\begin{array}{l}0.057 \\
(0.232)\end{array}$ & $\begin{array}{l}0.055 \\
(0.227)\end{array}$ & $\begin{array}{l}0.071 \\
(0.256)\end{array}$ & $\begin{array}{l}0.061 \\
(0.239)\end{array}$ & $\begin{array}{l}0.088 \\
(0.283)\end{array}$ & $\begin{array}{l}0.057 \\
(0.232)\end{array}$ & $\begin{array}{l}0.092 \\
(0.289)\end{array}$ & $\begin{array}{l}0.064 \\
(0.245)\end{array}$ & $\begin{array}{l}0.060 \\
(0.237)\end{array}$ \\
\hline ACE5 & $\begin{array}{l}0.044 \\
(0.206)\end{array}$ & $\begin{array}{l}0.036 \\
(0.187)\end{array}$ & $\begin{array}{l}0.039 \\
(0.194)\end{array}$ & $\begin{array}{l}0.081 \\
(0.273)\end{array}$ & $\begin{array}{l}0.042 \\
(0.201)\end{array}$ & $\begin{array}{l}0.073 \\
(0.260)\end{array}$ & $\begin{array}{l}0.044 \\
(0.205)\end{array}$ & $\begin{array}{l}0.071 \\
(0.256)\end{array}$ & $\begin{array}{l}0.045 \\
(0.206)\end{array}$ & $\begin{array}{l}0.044 \\
(0.205)\end{array}$ \\
\hline ACE6 & $\begin{array}{l}0.026 \\
(0.158)\end{array}$ & $\begin{array}{l}0.021 \\
(0.143)\end{array}$ & $\begin{array}{l}0.021 \\
(0.143)\end{array}$ & $\begin{array}{l}0.042 \\
(0.201)\end{array}$ & $\begin{array}{l}0.026 \\
(0.159)\end{array}$ & $\begin{array}{l}0.043 \\
(0.203)\end{array}$ & $\begin{array}{l}0.024 \\
(0.154)\end{array}$ & $\begin{array}{l}0.053 \\
(0.225)\end{array}$ & $\begin{array}{l}0.025 \\
(0.155)\end{array}$ & $\begin{array}{l}0.025 \\
(0.156)\end{array}$ \\
\hline ACE7 & $\begin{array}{l}0.017 \\
(0.128)\end{array}$ & $\begin{array}{l}0.014 \\
(0.117)\end{array}$ & $\begin{array}{l}0.011 \\
(0.106)\end{array}$ & $\begin{array}{l}0.025 \\
(0.157)\end{array}$ & $\begin{array}{l}0.015 \\
(0.121)\end{array}$ & $\begin{array}{l}0.031 \\
(0.174)\end{array}$ & $\begin{array}{l}0.016 \\
(0.125)\end{array}$ & $\begin{array}{l}0.035 \\
(0.183)\end{array}$ & $\begin{array}{l}0.017 \\
(0.129)\end{array}$ & $\begin{array}{l}0.017 \\
(0.127)\end{array}$ \\
\hline ACE8 & $\begin{array}{l}0.006 \\
(0.077)\end{array}$ & $\begin{array}{l}0.003 \\
(0.053)\end{array}$ & $\begin{array}{l}0.004 \\
(0.059)\end{array}$ & $\begin{array}{l}0.011 \\
(0.102)\end{array}$ & $\begin{array}{l}0.005 \\
(0.070)\end{array}$ & $\begin{array}{l}0.014 \\
(0.117)\end{array}$ & $\begin{array}{l}0.006 \\
(0.079)\end{array}$ & $\begin{array}{l}0.016 \\
(0.124)\end{array}$ & $\begin{array}{l}0.006 \\
(0.079)\end{array}$ & $\begin{array}{l}0.006 \\
(0.076)\end{array}$ \\
\hline
\end{tabular}

a. Standard deviations are in parentheses. Means and standard deviations are weighted by the BRFSS sample weight factor. All means are statistically significant using two tailed t-test with $95 \%$ confidence interval.

Prevalence of Adverse Childhood Experiences: The prevalence of the individual ACEs by selected variables, shown in Table 3, is calculated with the BRFSS sampling weighting factor. ACE exposure was more common in participants who completed less than 12 years of formal schooling, participants with household income less than $\$ 20,000$, and participants who were current smokers. Especially participants with household income less than $\$ 20,000$ and current smokers had relatively higher prevalence of ACEs than other groups across all individual adverse childhood experience categories. In contrast, respondents who were married and White non-Hispanic were relatively less exposed to ACEs. The prevalence of accumulative ACE scores is also calculated, shown in Table 4. Male, married, and White, non-Hispanic, have less exposure of ACEs than other adults as the ACE scores rise while prevalence for less than high school education, household income less than $\$ 20,000$, and current smokers falls as increasing in the accumulative ACE scores. 
Multiple Regression Results: In the BRFSS survey, the Disproportionate Stratified Sample (DSS) design for landline telephone samples and random sample for cellular telephone survey is used. The BRFSS provides the final weight factor to each respondent; however, the multiple regression estimates are employed without the BRFSS weight factor since the previous studies (DuMouchel \& Duncan, 1983; Chou et al., 2004; Son \& Lee, 2014) conduct an un-weighted regression analysis due to the BRFSS stratification sampling method. The overall model fits in terms of R-squared scores ranging from $13.2 \%$ to $16.7 \%$, in Tables 5 and 6, are relatively low because of the facts that primary determinants of health conditions, such as chronic health problems and health conditions: diabetes, heart diseases, insulin use, etc. (Clifford et al., 2013; Simms et al., 2013), are not accounted in the empirical models. It should be explored, but this study aims to investigate the effect of ACEs on HRQOL rather than to explain how the core determinants of health influence HRQOL.

Previous studies report ACEs are highly interrelated as described in the empirical implementation section, and it is possible that there might be important interaction among the demographic variables themselves. The data in this study are, therefore, inherently more likely to suffer from multicollinearity. Essentially, the more highly correlated independent variables are, the more difficult it becomes to accurately estimate the coefficients of the true model. The author explores whether the independent variables are correlated enough to have a significant effect on the estimation of the empirical equations. First of all, to detect the severity of multicollinearity, the simple correlation coefficient among independent variables is examined. The highest value of the estimated simple correlation coefficients for socio-demographic and health-behavioral variables is -0.44 between age and employed. The next highest score is 0.36 between married and income less than $\$ 20,000$. The other values of estimated coefficients are less than the absolute value of 0.30 . For the ACE variables, the estimated values of the simple correlation coefficients are 0.44 and 0.43 between physical abuse and emotional abuse and between physical abuse and domestic violence respectively. Other coefficients are less than the absolute value of 0.40 . Second, the High Variance Inflation Factors (VIFs) are calculated (Studenmund, 1992; Cohen et al., 2003). The calculated VIFs for all explanatory variables range from 1.32 to 2.32 . The results indicate some correlation, but not enough overly concern about. In overall, there are no significant evidences that the regressions coefficients are poorly estimated due to multicollinearity.

The socio-demographic variables: The multiple regression results with individual ACEs are shown in Table 5 . The number of physically unhealthy days increases with increasing age, whereas the number of mentally unhealthy days decreases generally with increasing age. The results are matched with the findings in the studies (Ford et al., 2003; Wang, 2008) that investigate the HRQOL. The studies find that the health status deteriorates as age increases, whereas the number of poor mental health days falls as age increases from the results of a series of regression models. In Table 5, males are more likely to have physically unhealthy days and less likely to have mentally unhealthy days. These results are contrary of the results from the studies (Wang, 2008; Heath \& Brown, 2009). They find that sex is found to be a significant predictor and that males are negatively associated with the number of days physical health was not good during the past 30 days, but males are positively related to the number of days mental health was not good. The signs of the estimated coefficients for the married are negative. The negative signs indicate that participants who were married are less likely to have both physically and mentally unhealthy days. The finding is consistent with the results from the study (Ahluwalia et al., 2003) while it is opposite to the results from the study (Clifford et al., 2013) that reports the married respondents are more likely to have unhealthy days.

The study by Heath and Brown (2009) examines the independent relationship between recommended physical activity and measures of HRQOL and uses multivariable logistic regression to obtain odds ratios. The odds of having 14 or more unhealthy days (physical or mental) during the past 30 days are greater for persons with a high school education or less. The result implies that lower education levels negatively affect health outcomes. Similarly, survey participants, in this study, who completed less than 12 years of formal schooling, have a higher risk for physical/mental health outcomes. Respondents who are employed are negatively associated with both physically and mentally unhealthy days. The estimates indicate that respondents who are employed have about 2.3 days and 1.4 days in which they are less likely to have physically and mentally unhealthy days respectively during the past 30 days. The results are significant for the predicting the number of, especially, physically unhealthy days. Since the estimated constant for measures of physical health outcomes is 2.47 days, participants who are employed have a likelihood of having no 
physically unhealthy days during the past 30 days. The results are supported by the study (Heath \& Brown, 2009) that uses multivariable logistic regression to obtain odds ratios. The odd of having 14 or more unhealthy days (physical or mental) during the past 30 days was greater for persons unemployed than those persons with employed status.

Table 5: Physically and Mentally Healthy Days Regressions with Individual Adverse Childhood Experiences $^{\mathrm{a}}$

\begin{tabular}{lll}
\hline Independent variable & Dependent variable: PHYSHLTH & Dependent variable: MENTHLTH \\
\hline Constant & $2.468(5.770)$ & $4.278(11.176)$ \\
Age & $0.021(5.293)$ & $-0.049(-14.043)$ \\
Male & $0.114(1.013)^{\mathrm{b}}$ & $-0.635(-6.286)$ \\
Married & $-0.011(-0.094)^{\mathrm{b}}$ & $-0.561(-5.306)$ \\
Less high school & $1.096(5.348)$ & $0.356(1.941)^{\mathrm{e}}$ \\
Employed & $-2.285(-18.189)$ & $-1.394(-12.402)$ \\
Less $\$ 20,000$ & $2.720(17.442)$ & $2.021(14.483)$ \\
White non-Hispanic & $0.618(4.100)$ & $0.573(4.249)$ \\
Body mass index & $0.104(11.615)$ & $0.082(10.206)$ \\
Current smokers & $1.159(7.956)$ & $1.869(14.339)$ \\
Current drinkers & $-1.334(-11.409)$ & $-0.352(-3.366)$ \\
Current exercise & $-3.687(-28.265)$ & $-1.718(-14.713)$ \\
Physical abuse & $0.784(4.181)$ & $0.963(5.742)$ \\
Emotional abuse & $0.709(5.013)$ & $0.966(7.634)$ \\
Sexual abuse & $1.260(6.733)$ & $2.308(13.780)$ \\
Mental Illness & $1.060(6.241)$ & $1.817(11.953)$ \\
Substance abuse & $0.349(2.241)$ & $0.282(2.185)$ \\
Incarceration & $0.368(1.478)^{\mathrm{b}}$ & $0.672(3.014)$ \\
Separation or divorce & $0.248(1.730)^{\mathrm{b}}$ & $0.181(1.412)^{\mathrm{b}}$ \\
Domestic violence & $0.067(0.379)^{\mathrm{b}}$ & $0.235(1.481)^{\mathrm{b}}$ \\
R Squared & 0.157 & 0.138 \\
\hline
\end{tabular}

a. The t-statistics are in parentheses. All regressions include state dummies not shown. All estimated coefficients are statistically significant at 95 percent level of confidence except bs.

The annual income less than $\$ 20,000$ is positively associated with both physically and mentally unhealthy days. The results show that participants who earn annual incomes less than $\$ 20,000$ are more likely to have unhealthy days. The estimated coefficients are 2.70 and 2.02 for HRQOL measures of physically and mentally unhealthy days respectively. They are the largest coefficients among the estimated coefficients for all independent variables except the coefficients of the ACEs. The studies (Ahluwalia et al., 2003; Wang, 2008) also find that the income level is a significant predictor and negatively influence the number of unhealthy days. The study by Jiang and Hesser (2008) examines the association between patterns of HRQOL and demographic, health risk, and health condition covariates. The results indicate that White, non-Hispanic, is less likely to have 14 or more physically unhealthy days, but more likely to have 14 or more mentally unhealthy days. Another study (Heath \& Brown, 2009) finds that White, non-Hispanic is less likely to have 14 or more unhealthy days (physical or mental). Nevertheless, this study finds that White non-Hispanic has more both physically and mentally unhealthy days than all other races.

The health behavioral variables: BMI is negatively associated with both measures of physical and mental health outcomes. Participants who are current smokers would have an additional 1.16 days and 1.87 days of physically and mentally unhealthy days respectively during the past 30 days compared with non-current smokers. Current drinkers are positively linked to both physical and mental health outcomes. Current drinkers have 1.33 days and 0.35 days less likely to have physically and mentally unhealthy days respectively than non-current drinkers. Current exercise is significantly beneficial in both physical and mental health outcomes. The estimates indicate that respondents who participate in any physical activities or exercises during the past month have three and a half days less physically unhealthy days than those who did not participate. However, the result is questionable because respondents who already have a physical problem may have difficult to participate in the physical activities. The elasticities of unhealthy days with respect to 
current exercise are -0.75 and -0.36 for physically and mentally unhealthy days respectively. The results imply that a $10 \%$ increase in the population of those who participate in any physical activities or exercises would lower physically and mentally unhealthy days by $7.5 \%$ and $3.6 \%$ respectively. The elasticities are computed from the regression models, $h=\beta_{0}+\beta_{k} x$. The elasticities $(\varepsilon)$ of percentage change in the number of unhealthy days with respect to the current exercise are computed as following: $\varepsilon=\frac{\% \Delta \mathrm{h}}{\% \Delta \mathrm{x}}=\frac{\mathrm{dh} / \mathrm{h}}{\mathrm{dx} / \mathrm{x}}=\frac{\mathrm{dh}}{\mathrm{dx}} \frac{\mathrm{x}}{\mathrm{h}}=\beta_{\mathrm{k}} \frac{\mathrm{x}}{\mathrm{h}}$, where $\beta_{\mathrm{k}}$ is the estimated coefficient in Table $5, \mathrm{x}$ is weighted mean of the current exercise, and $\mathrm{h}$ is the weighted mean of the number of unhealthy days in Table 1.

ACEs Results: Signs of the estimated coefficients of individual ACEs in Table 5 are all positive. The positive signs infer that all of the individual ACEs are inversely associated with the physical and mental health outcomes in adulthood. The estimated coefficients in magnitude for the mentally unhealthy days exceed the estimated coefficients for the physically unhealthy days except substance abuse and separate or divorce categories. The multiple regression results with accumulative ACEs are shown in Table 6. The estimated coefficients (not shown) for socio-demographic and health behavioral variables are similar to the estimated coefficients from the regression results with individual ACEs. Respondents who have only one of the adverse childhood experiences are likely to have additional 0.72 days and 0.56 days of physically and mentally unhealthy days respectively during the past 30 days. Respondents who have all eight categories of ACEs are likely to have an additional 4.74 days and 8.31 days of physically and mentally unhealthy days respectively than respondents who have none of the ACEs. Both physically and mentally unhealthy days increase as the accumulative ACE scores rise. This dosage effect is greater in negative mental health outcomes than in negative physical health outcomes. In comparison to the estimated coefficients in magnitude for accumulative ACE scores between physically and mentally unhealthy days, the gap increases as the ACE score rises for an ACE score of 1 and above. In short, the negative effects of the adverse childhood experiences on mental health outcomes are obviously greater than on physical health outcomes for either regression analyses with individual ACEs and with accumulative ACE scores.

Table 6: Physically and Mentally Healthy Days Regressions with Accumulative Adverse Childhood Experiences $^{\mathbf{a}}$

\begin{tabular}{lll}
\hline Independent variable & Dependent variable: PHYSHLTH & Dependent variable: MENTHLTH \\
\hline ACE0 & - & - \\
ACE1 & $0.716(5.137)$ & $0.560(4.479)$ \\
ACE2 & $1.254(7.022)$ & $1.470(9.173)$ \\
ACE3 & $2.025(9.607)$ & $2.306(12.192)$ \\
ACE4 & $2.204(8.939)$ & $2.940(13.24)$ \\
ACE5 & $3.166(10.740)$ & $4.691(17.735)$ \\
ACE6 & $3.291(8.686)$ & $4.960(14.590)$ \\
ACE7 & $3.628(7.476)$ & $6.004(13.785)$ \\
ACE8 & $4.738(5.892)$ & $8.309(11.515)$ \\
R Squared & 0.156 & 0.132 \\
\hline
\end{tabular}

a. The t-statistics are in parentheses. All regressions include demographic variables, health behavior variables, and state dummies not shown. All estimated coefficients are statistically significant at 95 percent level of confidence.

In addition to the multiple regression analyses, the study compares the average number of physically and mentally unhealthy days by the ACE categories. Figure 1 shows the comparison in the average number of unhealthy days by the individual ACEs. The average numbers of mentally unhealthy days are bigger than the average numbers of physically unhealthy days in every category. Figure 2 shows the comparison in the average numbers of both physically and mentally unhealthy days by accumulative ACE scores. The average numbers of mentally unhealthy days are significantly higher for an ACE score of 3 and above than the average numbers of physically unhealthy days during the past 30 days. These two figures also reveal that the effects of ACEs on mental health are greater than the effects of ACEs on physical health. 


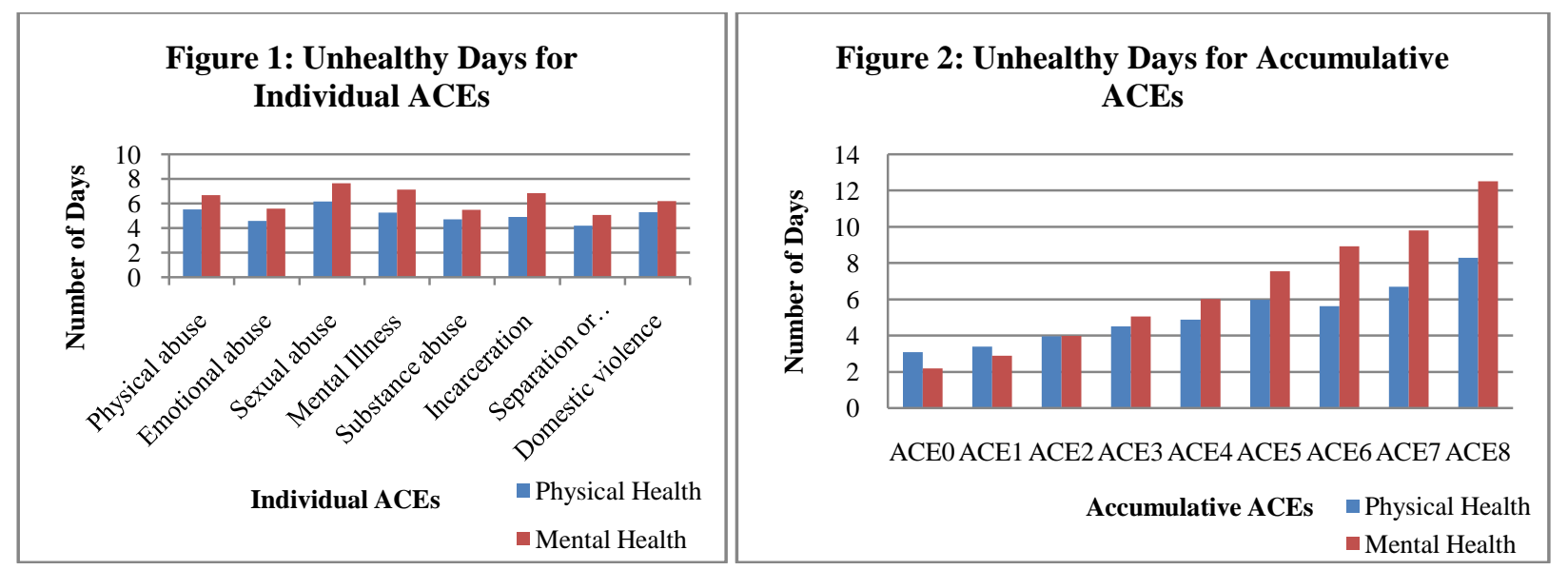

\section{Conclusion}

The number of physically and mentally unhealthy days as a measure of the health-related quality of life from the 2012 BRFSS data is examined. The regression results indicate that all individual ACE categories are inversely associated with both physical and mental health and that two individual ACE categories, sexual abuse and mental illness, tend to have particularly strong influences on physical and mental health outcomes compared to other categories of adverse childhood experiences. The estimated coefficients in magnitude on the mental health outcome are, in overall, larger than the estimated coefficients on the physical health outcome. From the regression results with accumulative ACE scores in Table 6, an increase in the number of both physically and mentally unhealthy days is observed as the ACE score rises. The estimated coefficients of ACE scores on the mental health outcome surpass the coefficients of ACE scores on physical health outcome for an ACE score of 2 and above. The gap in the estimated coefficients between physically unhealthy days and mentally unhealthy days increases with increasing the ACE score. The coefficient for the mentally unhealthy days at the ACE score of 8 becomes nearly twice as large as the coefficient for the physically unhealthy days. The survey participants who reported any of the adverse childhood experiences are likely to have more mentally unhealthy days than physically unhealthy days in comparison to the average days in Figure 1 . The comparison of average numbers of the physically and mentally unhealthy days for the ACE scores reaches similar results to the regression analyses as shown in Figure 2. In a summary of the empirical analyses, respondents who are exposed to any adverse childhood experience are observed as an increase in the likelihood of having physically- and mentally-related poor HRQOL in adulthood. The effect of ACE scores also indicates that higher levels of the ACE score would affect higher negative health outcomes, such as the dosage effects that appeared again in this study. Importantly, the negative effects of ACEs on mental health outcomes are significantly greater than the negative effects on physical health outcomes.

The study has limitations to using the measure of HRQOL from the BRFSS although previous literature has proven reliability of the measure of HRQOL from the BRFSS, and it has been widely used in health research. First of all, the numbers of unhealthy days during the past 30 days, measures of HRQOL, are collected as continuous variables. As described in the empirical implementation section, some clinicians and clinical researchers have dichotomized the measures of HRQOL using a cutoff value, and the author concerns the problematic method about the cut-off point. In consequence, this study keeps continuous HRQOL variables in the models (Zullig \& Hendryx, 2010), but it results in the predicted values that could be outside of a meaningful range between 0 and 30. Second, the BRFSS participants are asked for the number of unhealthy days during the past 30 days. No participants may record their health status on a daily basis and remember their health status accurately at the time of the interview. The participants may answer simple numbers of unhealthy days, such as $0,5,10,15,20,25$, and 30 . For instance, $30.94 \%$ (for physically unhealthy days) and $40.00 \%$ (for mentally unhealthy days) of respondents who reported one or more unhealthy days excluding 30 days actually reported $5,10,15,20$, or 25 which were easy numbers to answer the questions. Thus the numbers of unhealthy days may not be individual participants' exact numbers of unhealthy days. Third, the self-reported health status may not be subjective by the individual participant. There is no standard measure 
of health status. The self-reported health outcomes are just individual participants' self-perceptions of mental and physical health.

For the limitation of ACEs, respondents may be reluctant to report about their adverse childhood experiences. The ACE data from the BRFSS is probably under-reporting. For instance, the adverse childhood experiences modules in the BRFSS have high refusal rates compared to other refusal rates. According to the 2012 BRFSS code book for the five states, an average refusal rate of $4.58 \%$ from the survey participants for ACE questions is relatively higher than the refusal rates for other questions. Also, the 'yes' or 'no' questions for the ACEs absent measures of the level or frequency of adverse childhood experiences. Impact of different levels of ACEs may vary in health outcomes in adulthood. In addition, health status for aged participants may be mainly determined by other health-risk factors rather than the ACEs because elderly people are more likely to be emotionally depressed and vulnerable to get physical health issues (Acree et al., 2006). Thus, the effect of the ACEs on health outcomes may be subtle in later life. Respondents averaged 47.57 years of age in this study. As a result of the higher average age, the empirical estimates of the health outcomes due to the adverse childhood experiences may be questionable. On the other hand, the positive association of the individual ACEs and ACE scores with the number of physically and mentally unhealthy days implies that the consequences of ACEs may persist for several decades after their occurrence since the regression results for the individual ACEs and ACE scores, in general, are statistically significant. This suggests the persistence of the effect of ACEs in a lifetime should be examined in the future study.

The evidence that the impact of childhood adversities persists well into adulthood indicates the critical need for prevention and intervention strategies targeting early adverse experiences and their physical and mental health consequences. The early intervention during adolescence may mitigate long-term consequences of ACEs. Strategies to prevent adverse childhood experiences and provide resources for adults who experienced them may help improve the public health. According to the study Chartier et al. (2010), the ACEs are more likely to be found in environments where families are exposed to poor behavioral, emotional and cognitive child outcomes, such as poverty, domestic violence, mental health problems, substance abuse, incarceration and those led by single or teenage parents. It may be important to incorporate prevention and treatment of ACEs in affected families and to educate family members about child development and the burden that ACEs place on later stages of life. In summary, his study finds that the effects of ACEs on physical and mental health outcomes in adulthood are significantly different. This result adds to the existing literature by increasing awareness of the fact that the long-term negative consequences of ACEs on mental health outcomes are significantly greater than the negative effects on physical health outcomes.

\section{References}

Acree, L. S., Longfors, J., Fjeldstad, A. S., Fjeldstad, C., Schank, B., Nickel, K. J., Montgomery, P. S. \& Gardner, A. W. (2006). Physical Activity Is Related to Quality of Life in Older Adults. Health and Quality of Life Outcomes, 4(37). Published online 2006 Jun 30. doi: 10.1186/1477-7525-4-37.

Adam, E. K., Chyu, L., Hoyt, L. T., Doane, L. D., Boisjoly, J., Duncan, G. J., Chase-Lansdale, L. \& McDade, T. W. (2011). Adverse Adolescent Relationship Histories and Young Adult Health: Cumulative Effects of Loneliness, Low Parental Support, Relationship Instability, Intimate Partner Violence, and Loss. Journal of Adolescent Health, 49, 278-286.

Ahluwalia, I. B., Holtzman, D., Mack, K. A. \& Mokdad, A. (2003). Health-Related Quality of Life among Women of Reproductive Age: Behavioral Risk Factor Surveillance System (BRFSS), 1998-2001. Journal of Women's Health, 12, 5-9.

Anda, R. F., Felitti, V. J., Douglas B. J., Walker, J. D., Whitfield, C., Perry B. D., Dube, S. R. \& Giles, W. H. (2006). The Enduring Effects of Abuse and Related Adverse Experiences in Childhood. Eur Arch Psychiatry Clin Neurosci, 256, 174-186.

Andreson, E. M., Catlin, T. K., Wyrwich, K. W. \& Jackson-Thompson, J. (2003). Retest Reliability of Surveillance Questions on Health Related Quality of Life. Journal of Epidemiology and Community Health, 57, 339343.

Braveman, P. \& Gottlieb, L. (2014). The Social Determinants of Health: It's Time to Consider the Causes of the Causes. Public Health Reports, 129, 19-31. 
Brown, M. J., Thacker, L. R. \& Cohen, S. A. (2013). Association between Adverse Childhood Experiences and Diagnosis of Cancer. PLoS ONE, 8(6): e65524. doi:10.1371/journal.pone.0065524.

Brown, W. J., Trost, S. G., Bauman, A., Munnery, k. \& Owen, N. (2004). Test-Retest Reliability of Four Physical Activity Measures used in Population Surveys. Journal of Science and Medicine in Sport, 7, 205-215.

Cerne, A., Svab, I., Kersnik, J. \& Selic, P. (2013). Did Past Economic Prosperity Affect the Health Related Quality of Life Predictors? A Longitudinal Study on a Representative Sample of Slovenian Family Medicine Patients. BMC Public Health, 13(1160), doi: 10.1186/1471-2458-13-1160.

Chapman, D. P., Liu, Y., Presley-Cantrell, L. R., Edwards, V. J., Wheaton, A. G., Perry, G. S. \& Croft J. B. (2013). Adverse Childhood Experiences and Frequent Insufficient Sleep in 5 U.S. States, 2009: a Retrospective Cohort Study. BMC Public Health, 13 (3), 1-9.

Chartier, M. J., Walker, J. R. \& Naimark, B. (2010). Separate and Cumulative Effects of Adverse Childhood Experiences in Predicting Adult Health and Health Care Utilization. Child Abuse \& Neglect, 34, 454464.

Chen, H. Y., Baumgardner, D. J., Rice, J. P. (2011). Health-Related Quality of Life Among Adults With Multiple Chronic Conditions in the United States, Behavioral Risk Factor Surveillance System, 2007. Preventing Chronic Disease, 8, 1-9.

Chou, S., Grossman, M. \& Saffer, H. (2004). An Economic Analysis of Adult Obesity: Results from the Behavioral Risk Factor Surveillance System. Journal of Health Economics, 23, 565-587.

Clifford, E. L., Collins, M. M., Buckley, C. M., Fitzgerald, A. P. \& Perry, I. J. (2013). Unhealthy Days and Quality of Life in Irish Patients with Diabetes. PLoS ONE, 8 (12): e81102. Doi:10.1371/journal.pone.0081102.

Cohen, J., Cohen, P., West, S. G. \& Aiken, L. S. (2003). Applied Multiple Regression/Correlation Analysis for the Behavioral Sciences. Lawrence Erlnaum Associated, Inc., Mahawah, NJ.

DuMouchel, W. \& Duncan, G. J. (1983). Using Sample Survey Weights in Multiple Regression Analysis of Stratified Samples. Journal of the American Statistical Association, 78, 535-543.

Evenson, K. R. \& McGinn, A. P. (2005). Test-Retest Reliability of Adults Surveillance Measures for Physical Activity and Inactivity. American Journal of Preventive Medicine, 28, 470-478.

Ford, E. S., Anda, R. F., Edwards, V. J., Perry, G. S., Zhao, G., Li, C. \& Croft, J. B. (2011). Adverse Childhood Experiences and Smoking Status in Five States. Preventive Medicine, 53, 188-193.

Ford, E. S., Mannino, D. M., Homa, D. M., Gwynn, C., Redd, S. C., Moriarty, D. G. \& Mokdad A. H. (2003). SelfReported Asthma and Health-Related Quality of Life. Chest, 123, 119-127.

Ford, E. S., Mokdad, A. H., Li, C., McGuire, L. C., Strine, T. W., Okiro, C. A., Brown, D. W. \& Zack, M. M. (2008). Gender Differences in Coronary Heart Disease and Health-Related Quality of Life: Findings from 10 States from the 2004 Behavioral Risk Factor Surveillance System. Journal of Women's Health, 17, 757768.

Heath, G. W. \& Brown, D. W. (2009). Recommended Levels of Physical Activity and Health Related Quality of Life among Overweight and Obese Adults in the United States. 2005. Journal of Physical Activity and Health, 6, 403-411.

Heslin, K. C., Stein, J. A., Heinzerling, K. G., Pan, D., Magladry, C. \& Hays, R. D. (2011). Clinical Correlates of Health-related Quality of Life among Opioid-dependent Patients. Qual Life Res, 20(8), 1205-1213.

Huang, C. Y., Hsu, M. C. \& Chen, T. J. (2012). An Exploratory Study of Religious Involvement as a Moderator between Anxiety, Depressive Symptoms and Quality of Life Outcomes of Older Adults. Journal of Clinical Nursing, 21, 609-618.

Jia, H. \& Lubetkin, E. I. (2009). Time Trends and Seasonal Patterns of Health-Related Quality of Life Among U.S. Adults. Public Health Report, 124, 692-701.

Jiang, Y. \& Hesser, J. E. (2008). Patterns of Health-related Quality of Life and Patterns Associated with Health Risks among Rhode Island Adults. Health and Quality of Life Outcomes, 6(49), doi: 10.1186/14777525-6-49.

Liu, Y., Croft, J. B., Chapman, D. P., Perry, G. S., Greenlund, K. J., Zhao, G. \& Edwards, V. J. (2013). Relationship between Adverse Childhood Experiences and Unemployment among Adults from five US States. Soc Psychiatry Psychiatr Epidemiol, 48, 357-369.

Maddala, G. S. (1992). Introduction to Economics, Second Edition, Macmillan Publishing Company, New York.

Mahabaleshwarkar, R., Khanna, R., West Strum, D. \& Yang, Y. (2013). Association between Health-Related Quality of Life and Colorectal Cancer Screening. Population Health Management, 16, 178-189. 
Mersky, J. P., Topitzes, J. \& Reynolds, A. J. (2013). Impacts of Adverse Childhood Experiences on Health, Mentalhealth, and Substance Use in Early Adulthood: A Cohort Study of an Urban, Minority Sample in the U.S. Child Abuse \& Neglect, 37, 917-925.

Mesbah, M. (2004). Measurement and Analysis of Health Related Quality of Life and Environment Data. Environmetrics, 15, 471-481.

Meyer, O. L., Castro-Schilo, L. \& Aguilar-Gaxiola, S. (2014). Determinants of Mental Health and Self-Rated Health: A Model of Socioeconomic Status, Neighborhood Safety, and Physical Activity. American Journal of Public Health, 104(9), 1734-1741.

Miles, A. \& Proescholdbell, R. J. (2011). Explaining Rural/non-rural Disparities in Physical Health-related Quality of Life: a Study of United Methodist Clergy. Quality of Life Research, 20, 807-815.

Montgomery, A. E., Cutuli, J. J., Evans-Chase, M., Treglia, D. \& Culhane, D. P. (2013). Relationship Among Adverse Childhood Experiences, History of Active Military Service, and Adult Outcomes: Homelessness, Mental Health, and Physical Health. American Journal of Public Health, 103, S262-S268.

Mostoufi, S. M., Strachan, E., Chopko, L., Succop, A., Martinez, B., Ahumada, S. M. \& Afari, N. (2013). Adverse childhood experiences, health perception, and the role of shared familial factors in adult twins. Child Abuse \& Neglect, 37, 910-916.

Schüsseler-Fiorenza Rose, S. M., Xie, D. \& Stineman, M. (2014). Adverse Childhood Experiences and Disability in U.S. Adults. American Academy of Physical Medicine and Rehabilitation, 6, 670-680.

Simms, K., Hacker, D. S., Parker, A. J., Figuereo, M. E. \& Bock, S. (2013). Do Past or Present Adverse Relationship experiences Have Greater Impact on Mental and Physical Health? Advances in Mental Health, 11(2), 122-130.

Son, C. H. \& Lee, D. H. (2014). The Effects of Alcohol Consumption Patterns on Cardiovascular Disease: An Empirical Study with Behavioral Risk Factor Surveillance System Data. The Empirical Economics Letters, 13(7), 723-730.

Studenmund, A. H. (1992). Using Econometrics (second edition). Harper Collins Publishers Inc., New York.

Theofilou, P. (2013). Quality of Life: Definition and Measurement. Europe's Journal of Psychology, 9(1), 150162.

Wang, Y. (2008). Physical Activities and Health-Related Quality of Life in Older Adults: Finding from the BRFSS 200. Annual in Therapeutic Recreation, XVI, 102-113.

Zullig, K. J. \& Hendryx, M. (2010). A Comparative Analysis of Health-Related Quality of Life for Residents of U.S. Counties with a without Coal Mining. Public Health Report, 125, 548-555. 